ISSN: 2594-4827

\title{
A DUALIDAdE DA EDUCAÇÃO NO BRASIL E OS DEZ ANOS DO INSTITUTO FEDERAL DE EDUCAÇÃO, CIÊNCIA E TECNOLOGIA DO NORTE DE MINAS GERAIS: UMA PROPOSTA DE TRAVESSIA
}

\author{
André Marcos de Sousa Nunes ${ }^{1}$ \\ Caio Bruno Wetterich ${ }^{2}$
}

Recebido em: agosto/2019

Publicado em: dezembro/2019

\section{RESUMO}

Esse artigo, a partir de revisão bibliográfica e análise documental, buscou investigar o processo histórico da educação profissional no Brasil e identificar os desafios e conquistas do Instituto Federal de Educação, Ciência e Tecnologia do Norte de Minas Gerais (IFNMG) na proposta de superar a dualidade educacional, ou seja, superar os modelos diferenciados de ensino conforme a classe social ocupada pelo indivíduo. Por meio de contribuições científicas de autores e análise de documentos institucionais confirma-se uma desigualdade estrutural na educação brasileira. Os resultados apontam que, na atualidade, os desafios enfrentados pelo IFNMG comprovam que há recuos significativos que o limita prosseguir na sua proposta, contudo, conquistas importantes ocorreram em uma década de existência.

Palavras-chave: educação profissional; dualidade educacional; IFNMG; desafios; conquistas.

\section{ABSTRACT}

This article, based on bibliographic review and documentary analysis, sought to investigate the historical process of professional education in Brazil and identify the challenges and achievements of the Federal Institute of Education, Science and Technology of northern Minas Gerais (IFNMG) in the proposal to overcome educational duality, that is, to overcome the differentiated models of teaching according to the social class occupied by the individual. Through scientific contributions from authors and analysis of institutional documents, a structural inequality in Brazilian education is confirmed. The results indicate that, nowadays, the challenges faced by IFNMG prove that there are significant setbacks that limit it to continue in its proposal, however, important achievements occurred in a decade of existence.

Keywords: professional education; educational duality; IFNMG; challenges; Achievements.

\footnotetext{
${ }^{1}$ Mestrando do Programa de Mestrado em Educação Profissional e Tecnológica do Instituto Federal de Educação, Ciência e Tecnologia do Norte de Minas Gerais. E-mail: andrenunes.ara@gmail.com

${ }^{2}$ Professor do Programa de Mestrado em Educação Profissional e Tecnológica do Instituto Federal de Educação, Ciência e Tecnologia do Norte de Minas Gerais. E-mail: caio.wetterich@ifnmg.edu.br
} 


\section{INTRODUÇÃO}

A educação brasileira desde a sua concepção foi marcada por uma desigualdade estrutural profunda tanto em relação ao modelo e a qualidade do ensino quanto ao acesso a esse ensino a depender da classe social que cada indivíduo ocupa. Para Moura (2007), desde o período imperial, a educação já cumpria a função de contribuir para a reprodução das classes sociais, já que aos filhos das elites estava assegurada a escola das ciências, das letras e das artes e aos demais lhes era negado o acesso.

Trazer o problema da dualidade educacional para o centro das discussões tem como tentativa de evidenciar o aspecto dicotômico da educação brasileira, objetivando a criação e/ou o fortalecimento de projetos alternativos de superação dessa desigualdade para uma educação integrada e omnilateral (MOURA, 2013). Para Frigotto (2018), por se tratar de um projeto comprometido com a promoção da diminuição das desigualdades sociais e regionais presentes na realidade brasileira, os institutos federais engajados com o desenvolvimento local das regiões onde se estabelecem apresentam uma possibilidade promover essa travessia.

Presente em dez municípios, composto por oito campi, dois campi avançados e uma reitoria, o IFNMG possui uma vasta área de atuação, o que demonstra a importância do desenvolvimento de estudos científicos sobre a instituição. Conforme é retratado por Pacheco (2015), a estrutura multicampi e a clara definição de território de abrangência das ações dos Institutos Federais afirmam, na missão dessas instituições, o compromisso de intervenção em suas respectivas regiões, identificando problemas e criando soluções técnicas e tecnológicas para o desenvolvimento sustentável com inclusão social.

Esse trabalho, a partir de uma revisão bibliográfica e análise documental, buscou investigar o processo histórico da educação profissional no Brasil e identificar os desafios e conquistas do Instituto Federal do Norte de Minas Gerais (IFNMG) na proposta de superar a dualidade educacional. Os documentos foram discutidos a partir da perspectiva de autores da área como: Celso Suckow da Fonseca, Dante Henrique Moura, Acácia Zeneida Kuenzer, Gaudêncio Frigotto, Maria Ciavatta e Elieser Pacheco. O conteúdo desse artigo está divido em quatro etapas: na primeira parte foi feita a contextualização do tema, o percurso metodológico estabelecido para a realização da pesquisa foi descrito na segunda etapa; na terceira etapa apresentou-se a discussão dos resultados da investigação apontando como ocorreu o processo histórico da educação profissional no Brasil e 
ISSN: 2594-4827

os principais desafios e conquistas do IFNMG no desenvolvimento de sua proposta de ensino; na quarta e última etapa foi realizada a conclusão da pesquisa.

\section{PERCURSO METODOLÓGICO}

A metodologia utilizada no desenvolvimento desse trabalho percorreu o caminho da pesquisa bibliográfica e análise documental.

Segundo Gil (1989), a pesquisa bibliográfica envolve as seguintes fases: exploração das fontes bibliográficas, leitura do material, elaboração das fichas, ordenação e análise das fichas e conclusão. Para o autor, não existem regras fixas para a realização desse tipo de pesquisa, mas ele destaca que a experiência demonstra que essas são tarefas importantes no processo. Seguindo o percurso apontado por Gil (1989), na exploração das fontes buscou-se artigos e livros de autores que tratam sobre o tema relacionado na bibliografia utilizada pelo curso do mestrado em Educação Profissional e Tecnológica (ProfEPT) e na sequência realizou-se a leitura das obras relacionando aquelas que buscavam responder os objetivos da investigação. Após resumo dos aspectos mais importantes das fontes que pudessem interessar na pesquisa, estes foram adequadamente ordenados em fichas segundo o seu conteúdo. Sequencialmente fez-se a discussão dos resultados e a conclusão da investigação a partir das diferentes contribuições científicas que nortearam este trabalho.

Com relação a análise documental, segundo Ludke e André (1986), essa constitui uma técnica valorosa de abordagem de dados qualitativos na área de educação, a qual pode ser utilizada tanto para complementar as informações obtidas por outras técnicas, como desvelar aspectos novos de um tema ou problema. Outra vantagem considerada para a utilização da análise de dados documentais neste trabalho foi pela possibilidade de conhecimento do passado, que conforme foi descrito por Gil (2008, p. 153) "por terem sido elaborados no período que se pretende estudar, são capazes de oferecer um conhecimento mais objetivo da realidade".

Para Severino (2007, p. 124), “a documentação compreende toda forma de registro e sistematização de dados, colocando-os em condições de análise por parte do pesquisador". Sobre o assunto, Gil (2008) declara que, para fins de pesquisa científica tanto os documentos escritos utilizados para esclarecer alguma coisa, quanto qualquer objeto que possa contribuir para a investigação de determinado fato ou fenômeno deverão ser considerados. O autor também aponta algumas fontes que poderão ser utilizadas como documentação, tais como: registros estatísticos, documentos pessoais, documentos de comunicação de massa e registros institucionais escritos. 
Nesse sentido, foram analisados os seguintes documentos institucionais disponíveis no Portal do IFNMG: Plano de Desenvolvimento Institucional - PDI, Relatório de gestão, legislações e o documento denominado IFNMG em números. Os dados levantados foram discutidos, posteriormente, conforme o ponto de vista de autores da área como: Celso Suckow da Fonseca, Dante Henrique Moura, Acácia Zeneida Kuenzer, Gaudêncio Frigotto, Maria Ciavatta e Elieser Pacheco.

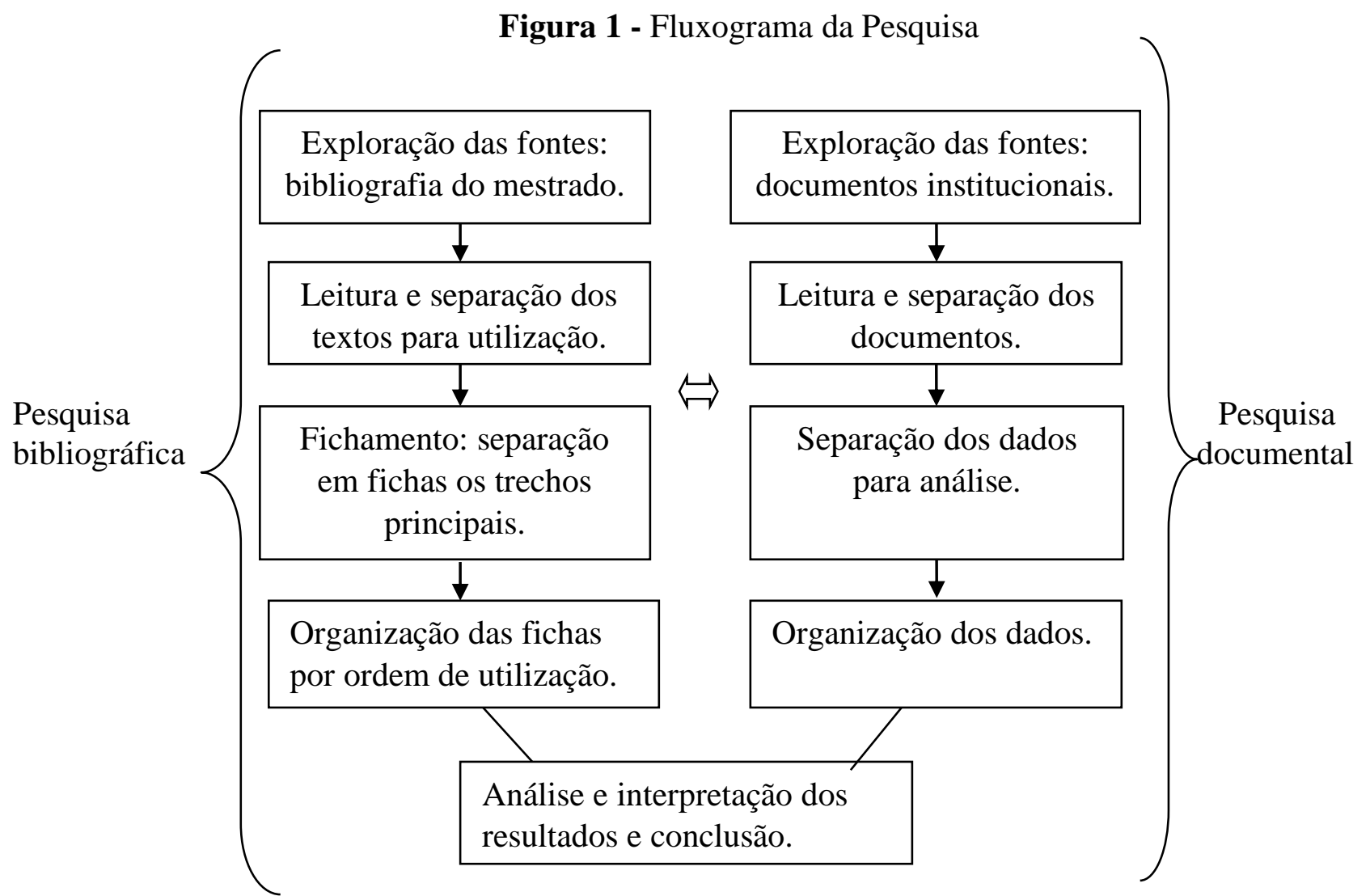

Figura 01: Fluxograma das etapas envolvidas nessa pesquisa.

Desenvolveu-se na pesquisa documental as mesmas etapas aplicadas na pesquisa bibliográfica, pois de acordo com Gil (2008), a diferença entre ambas está na natureza das fontes, podendo, portanto, seguir os mesmos passos. A figura 1 a seguir apresenta o fluxograma das etapas dessa pesquisa.

\section{RESULTADOS E DISCUSSÃO}

Nesta seção serão apresentados e discutidos os resultados dessa investigação. Assim, em conformidade com a revisão bibliográfica e documentos analisados, serão abordados os dados 
ISSN: 2594-4827

obtidos nos textos, livros, relatórios, planos e legislações que seguindo o método de exploração das fontes, leitura, classificação e fichamento das informações, procurou-se analisar e refletir como ocorreram as transformações na educação profissional no Brasil desde o período império-colonial e os principais desafios e conquistas do IFNMG em uma década de existência.

\section{A EDUCAÇÃO PROFISSIONAL NO BRASIL}

A educação profissional no país teve seu início marcado por opressão, condição correntemente comum imposta àqueles que não estavam em circunstâncias sociais e políticas favoráveis para opor resistência na época da colonização do Brasil (GARCIA, 2000; CUNHA, 2000). Conforme é apontado por Fonseca (1961), dissociado do processo de educação, o ensino de ofícios era destinado aos índios, escravos e mais tarde aos pobres e órfãos, com o objetivo apenas de passar os encargos pesados a que a vida rude da época exigia. Dessa forma, a educação profissional foi se transformado nesse período de acordo com o quadro 1.

Quadro 1- Linha do Tempo da Educação Profissional no período Império-colonial

\begin{tabular}{|c|l|}
\hline Período & \multicolumn{1}{|c|}{ Criações a alterações na legislação } \\
\hline 1822 a 1889 & $\begin{array}{l}\text { Criação das casas de Fundição e da Moeda e criação Centros de Aprendizagem de } \\
\text { Ofícios nos Arsenais da Marinha no Brasil }\end{array}$ \\
\hline 1808 & Criação do Colégio das Fábricas. \\
\hline 1840 a 1865 & $\begin{array}{l}\text { Implantação do Colégio de Educando e Artífices em dez províncias: Pará, } \\
\text { Maranhão, São Paulo, Piauí, Alagoas, Sergipe, Ceará, Rio Grande do Norte e } \\
\text { Paraíba. }\end{array}$ \\
\hline 1859 & Criação dos Liceus de Artes e ofícios \\
\hline
\end{tabular}

Fonte: Quadro elaborado pelo autor a partir das fontes: Fonseca (1961); MEC (2016).

Com o aparecimento do ouro em Minas Gerais e o surgimento das Casas de Fundição e da Moeda, onde se transformava o metal em barra e cunhavam as moedas que circulavam na época, surgiu a necessidade de alterar o modelo de aprendizagem de ofícios. Dessa forma, houve a necessidade de um ensino um pouco mais especializado, mas esse já era direcionado aos indivíduos brancos, filhos de colonos ou de funcionários da própria casa da moeda (FONSECA, 1961; NARCISO, 2015). Os autores acrescentam que juntamente com o ensino nas Casas da Moeda surge o primeiro processo de certificação por meio de banca examinadora constituída para avaliar as habilidades dos aprendizes. 
Para aqueles que não se enquadravam no modelo das Casas da Moeda no ciclo do ouro foram criados Centros de Aprendizagem de Ofícios Artesanais da Marinha do Brasil. Os aprendizes eram recrutados até durante a noite, quando uma patrulha do Arsenal saía e recolhia todo aquele que fosse encontrado vagando pelas ruas depois do toque de recolher (GARCIA, 2000). Segundo Cunha (2000), naquela época, com o objetivo de formar guarnições militares e navais, prendiam-se órfãos, abandonados, desvalidos, que eram encaminhados pelos juízes aos arsenais militares, onde eram internados e postos para trabalhar.

Pode-se perceber que até o século XIX não existiam propostas sistemáticas de experiências de ensino, o que prevalecia era educação propedêutica voltada apenas para as elites e sua formação como dirigentes (MOURA, 2007; SCOTT E MORAES, 2012). Moura (2007) acrescenta que já naquela época a educação cumpria a função de contribuir para a reprodução das classes sociais, já que aos filhos das elites estava assegurada essa escola das ciências, das letras e das artes e aos demais lhes era negado o acesso.

Fonseca (1961) aponta que no século XVIII já havia intenções de integrar os trabalhos relacionados aos ofícios à educação, porém, essa integração só foi possível no início do século seguinte. No decorrer do século XIX, surgem as primeiras propostas de experiência de ensino na educação profissional com a criação do Colégio das Fábricas em 1808 pelo Príncipe Regente, futuro D. João VI, época em que ficou marcada como o início da educação profissional no Brasil (GRACIA, 2000; SOCOTT E MORAES, 2012). Scott e Mores (2012) acrescentam que antes da implantação do Colégio das Fábricas havia outros estabelecimentos voltados para ensino profissional (no cais, no hospital, nos arsenais militares ou de marinha), porém, foi ele que serviu de referência para outros que vieram a ser implantados no país.

Outro ponto que merece destaque para o ensino de ofícios na época do império foi a instalação das Casas de Educandos Artífices em dez províncias.

Entre 1840 e 1856, foram criadas as Casas de Educandos Artífices por dez governos provinciais, que adotaram o modelo de aprendizagem de ofícios vigente no âmbito militar, inclusive os padrões de hierarquia e disciplina (CUNHA, 2012. p. 91).

Segundo Fonseca (1961), nesse período da nossa história, qualquer referência ao ensino de ofício era uma demonstração clara que se tratava de obra assistencial ou de caridade em que a educação profissional refugiou-se nos asilos, nos arsenais, nas Casas de Educandos Artífices direcionada àqueles abandonados da fortuna. Corroborando esse assunto, Moura (2007) entende que 
a educação profissional no Brasil além da perspectiva assistencialista para amparo dos órfãos e dos desvalidos da sorte tinha o objetivo de evitar que continuassem a praticar ações que estavam contra a ordem e os bons costumes.

Em contraposição a velha filosofia apontada como deprimente e desmoralizante do ensino de ofícios, Cunha (2000) descreve que ainda no século XIX começaram a ser organizadas pela sociedade civil instituições destinadas a amparar órfãos e/ou ministrar ensino de artes e ofícios, assim conseguiram compor um quadro de sócios beneméritos que as dirigiam e mantinham com seus próprios recursos ou com subsídios governamentais que atraíam. Moura (2007) complementa que entre estas instituições, as mais importantes foram os Liceus de Artes e Ofícios em várias capitais, que possibilitaram uma base de instrução teórica e prática iniciando as crianças órfãs e abandonadas no ensino industrial.

Quando apareceu em 1858, o Liceu de Artes e Ofícios do Rio de Janeiro começou, no Brasil, uma nova era para o ensino de ofícios. É que sendo o Liceu destinado a todas as classes sociais, representava uma reação contra a secular concepção do desprezo pelo trabalho das mãos. Suas lutas, suas dificuldades, e, principalmente sua projeção no tempo e no espaço, atestam que principiava a surgir uma mentalidade nova que tendia a modificar os velhos conceitos e a alterar a antiga maneira de encarar o problema (FONSECA, 1961, p. 652).

O Liceu de Artes e Ofícios tinha o objetivo de proporcionar a todos os indivíduos nacionais e estrangeiros, exceto os escravos, o estudo de belas-artes e sua aplicação necessária aos ofícios e indústrias, explicando-se os princípios científicos em que ela se baseia (CUNHA, 2000). Sobre esse assunto, Fonseca (1961) acrescenta que o Brasil atravessava a fase em que os produtos industriais eram, em sua maioria, executados a mão, o que demandava um senso artístico por parte dos operários e o Liceu veio trazer a chama do ideal da beleza unida à prática.

Entendido como um poderoso instrumento para a solução das questões sociais pelos industrialistas, o ensino profissional era cogitado a ser obrigatório antes mesmo de instituir leis sociais (CUNHA, 2000). Impulsionado pelo modelo das nações europeias com a questão industrial, decorreu então uma nova maneira de encarar a educação profissional no Brasil, com a criação das Escolas de Aprendizes e Artífices (FONSECA, 1961).

Mesmo com essa disposição dos Liceus, as iniciativas de educação profissional adotadas tanto pelo Estado como pela sociedade civil tinham objetivos claros, conforme se segue:

a) imprimir a motivação para o trabalho; b) evitar o desenvolvimento de ideias contrárias à ordem política, de modo a não se repetirem no Brasil as agitações que ocorriam na Europa; c) propiciar a instalação de fábricas que se beneficiariam da existência de uma oferta de força de trabalho qualificada, motivada e ordeira; e d) favorecer os próprios trabalhadores, 
que passariam a receber salários mais elevados, na medida dos ganhos de qualificação (CUNHA, 2000. p. 92).

Dessa forma, para o autor, foi constituído o legado do Império à República, no que se refere ao ensino de ofícios manufatureiros.

Em 1909, o presidente Nilo Peçanha assina o Decreto 7.566 em 23 de setembro, criando inicialmente 19 Escolas de Aprendizes Artífices subordinadas ao Ministério dos Negócios da Agricultura, Indústria e Comércio (FONSECA, 1961; KUENZER, 1991). Foi a partir dessa época que a educação profissional passou a ser pensada em nível nacional e organizada de forma sistemática.

Para alguns autores, mesmo com a sistematização do ensino e a criação das Escolas de Aprendizes Artífices, a educação não perdeu o seu caráter dual, ou seja, preparar os pobres, marginalizados desvalidos da sorte para as funções técnicas conforme descrito a seguir:

A finalidade manifestamente educacional das escolas de aprendizes artífices era a formação de operários e contramestres, através de ensino prático e conhecimentos técnicos necessários aos menores que pretendessem aprender um ofício em "oficinas de trabalho manual ou mecânico que forem mais convenientes e necessários ao estado em que funcionar a escola, consultadas, quanto possível, as especialidades das indústrias locais" (CUNHA, 2000. p. 95).

Nesse sentido, entende-se que a dualidade educacional advém do modo de produção capitalista que requer uma divisão social e técnica do trabalho para o seu fortalecimento, resultando na separação entre o trabalho intelectual e o trabalho manual, trabalho simples e trabalho complexo, cultura geral e cultura técnica (MOURA, LIMA FILHO E SILVA, 2015; KUENZER, 1991). Kuenzer (1991) acrescenta que a separação entre a teoria e a prática, conduz para uma estrutura dualista da educação que prepara diferentemente os homens para que atuem em posições hierárquica e tecnicamente diferenciadas no sistema produtivo.

Nessa mesma linha, Celso Suckow da Fonseca também acreditava no prosseguimento da desigualdade no ensino:

A República, proclamada tão pouco tempo depois da Lei Áurea, aceleraria a renovação das velhas ideias assim como a implantação de outra filosofia mais consentânea com os novos tempos. Apesar disto, quando, em 1909, Nilo Peçanha lançava seu famoso decreto criando uma Escola de Aprendizes Artífices em cada Estado da União ainda o fazia destinando-as aos deserdados da fortuna, numa demonstração clara de ter seu luminoso espírito ainda preso às antigas fórmulas (FONSECA, 1961. p. 655).

Após a instituição da educação profissional no Brasil, por meio da criação das Escolas de Artes e Ofícios até a criação do SENAI - Serviço Nacional de Aprendizagem Industrial em 1942, 
outros fatos importantes aconteceram para a consolidação da educação profissional, conforme o quadro 2 a seguir:

Quadro 2 - Linha do Tempo da Educação Profissional de 1927 a 1942

\begin{tabular}{|c|l|}
\hline Ano & \multicolumn{1}{c|}{ Criação e alterações da legislação } \\
\hline 1927 & $\begin{array}{l}\text { O Congresso Nacional sanciona o Projeto de Fidélis Reis, que prevê o oferecimento } \\
\text { obrigatório do ensino profissional no país. }\end{array}$ \\
\hline 1930 & $\begin{array}{l}\text { É criado o Ministério da Educação e Saúde Pública que passa a supervisionar as Escolas } \\
\text { de Aprendizes e Artífices, através da Inspetoria do Ensino Profissional Técnico. }\end{array}$ \\
\hline 1937 & $\begin{array}{l}\text { Promulgada a nova Constituição Brasileira que trata pela primeira vez do ensino técnico, } \\
\text { profissional e industrial. É assinada a Lei 378, que transforma as Escolas de Aprendizes e } \\
\text { Artífices em Liceus Industriais, destinados ao ensino profissional, de todos os ramos e } \\
\text { graus. }\end{array}$ \\
\hline 1941 & $\begin{array}{l}\text { Vigora uma série de leis, conhecidas como a Reforma de Capanema, que remodelam todo } \\
\text { o ensino no país. Os principais pontos foram: } \\
\text { - O ensino profissional passa a ser considerado de nível médio;- Os cursos são divididos } \\
\text { em dois níveis: curso básico industrial, artesanal de aprendizagem e de mestria, e o } \\
\text { segundo, curso técnico industrial. }\end{array}$ \\
\hline 1942 & $\begin{array}{l}\text { O Decreto 4.127, de 25 de fevereiro, transforma os Liceus Industriais em Escolas } \\
\text { Industriais e Técnicas, passando a oferecer a formação profissional em nível equivalente } \\
\text { ao do secundário. }\end{array}$ \\
\hline
\end{tabular}

Fonte: MEC (2016).

Sob a pressão do setor industrial e comercial em formar mão de obra com qualificação técnica para o preenchimento dos seus postos de trabalho, em 1942 foi criado o SENAI (Serviço Nacional de Aprendizagem Industrial) pelo Decreto-Lei no 4.048, de 22 de janeiro de 1942 e em 1946 foi criado o Serviço Nacional de Aprendizagem Comercial - Senac, pelo Decreto-Lei $\mathrm{n}^{\circ}$ 8.621, de 10 de janeiro de 1946, bem como a aprendizagem dos comerciários foi regulamentada pelo Decreto-Lei no 8.621, do mesmo dia 10 de janeiro de 1946 (FONSECA, 1961).

Segundo Kuenzer (1991), a criação dessas escolas explicitou ainda mais o caráter dual da educação brasileira, cuja proposta curricular era eminentemente prática, em que as preocupações com a formação teórica raramente apareciam em contrapartida às poucas escolas técnicas que foram criadas junto a escolas de engenharia na década de 1930. Sobre esse assunto, Fonseca (1961) esclarece que as escolas técnicas da Rede Federal do Ministério da Educação formam operários altamente qualificados, com formação integral, mais profunda e eclética. Já aqueles oriundos das 
escolas do SENAI, por meio de cursos aligeirados e superficiais e currículo exíguo, têm um preparo monotécnico.

Em 1946, por meio do Decreto-Lei no 9.613/46, conhecido como Lei Orgânica do Ensino Agrícola, tratou dos estabelecimentos do ensino agrícola federal e em 1959 foram instituídas as escolas técnicas federais como autarquias, a partir das escolas industriais e técnicas mantidas pelo Governo Federal. Já em 1967, as fazendas modelo foram transferidas do Ministério da Agricultura para o MEC e passaram a ser denominadas escolas agrícolas (MEC, 2016). Essas legislações foram importantes para o surgimento da Escola Agrotécnica Federal de Salinas e o Centro Federal de Educação de Januária. que futuramente se unificariam formando o IFNMG - Instituto Federal de Educação, Ciência e Tecnologia do Norte de Minas Gerais.

Em 1953, iniciava a construção da Escola de Iniciação Agrícola de Salinas, que deu início às aulas de formação de Operários Agrícolas Especializados em 1956 e, desde então, formou milhares de profissionais na área agrícola e, mais tarde, também em outras áreas. Em 1960, era fundada a Escola Agrotécnica Federal de Januária, unidade que ao longo de sua história passou por profundas transformações, inclusive de nomenclaturas (IFNMG, 2018). Até a criação dos Institutos Federais e a fusão das escolas de Salinas e Januária que resultaria no IFNMG em 2008, muitas outras mudanças ocorreram no âmbito da educação profissional conforme o quadro 3 a seguir:

Quadro 3 - Linha do Tempo da Educação Profissional de 1959 a 2007

\begin{tabular}{|l|l|}
\hline Ano & \multicolumn{1}{|c|}{ Criação e Alterações da Legislação } \\
\hline 1959 & $\begin{array}{l}\text { As escolas Industriais e Técnicas são transformadas em autarquias com o nome de Escolas } \\
\text { Técnicas Federais, com autonomia didática e de gestão. }\end{array}$ \\
\hline 1961 & $\begin{array}{l}\text { O ensino profissional é equiparado ao ensino acadêmico com a promulgação da Lei 4.024, } \\
\text { que fixa as Diretrizes e Bases da Educação Nacional. O período é marcado por profundas } \\
\text { mudanças na política de educação profissional. }\end{array}$ \\
\hline 1967 & $\begin{array}{l}\text { Decreto 60.631 transfere as Fazendas Modelos do Ministério da Agricultura para o } \\
\text { Ministério da Educação e Cultura, que passam a funcionar como escolas agrícolas. }\end{array}$ \\
\hline 1971 & $\begin{array}{l}\text { A Lei de Diretrizes e Bases da Educação Brasileira torna técnico-profissional todo } \\
\text { currículo do segundo grau compulsoriamente. Um novo paradigma se estabelece: formar } \\
\text { técnicos sob o regime de urgência. }\end{array}$ \\
\hline 1978 & $\begin{array}{l}\text { A Lei 6545 transforma três Escolas Técnicas Federais (Paraná, Minas Gerais e Rio de } \\
\text { Janeiro) em Centros Federais de Educação Tecnológica. }\end{array}$ \\
\hline 1994 & \begin{tabular}{l} 
A Lei 8948, de 8 de dezembro: \\
\hline
\end{tabular}
\end{tabular}




\begin{tabular}{|c|c|}
\hline & $\begin{array}{l}\text { - Institui o Sistema Nacional de Educação Tecnológica, transformando, gradativamente, as } \\
\text { ETFs e as EAFs em CEFETs; } \\
\text { - A expansão da oferta da educação profissional somente ocorrerá em parceria com } \\
\text { Estados, municípios e Distrito Federal, setor produtivo ou organizações não } \\
\text { governamentais, que serão responsáveis pela manutenção e gestão dos novos } \\
\text { estabelecimentos de ensino. }\end{array}$ \\
\hline 1996 & $\begin{array}{l}\text { Em } 20 \text { de novembro, a Lei } 9394 \text { (Lei de Diretrizes e Bases da Educação Nacional - LDB) } \\
\text { dispõe sobre a Educação Profissional num capítulo próprio. }\end{array}$ \\
\hline 1997 & $\begin{array}{l}\text { O Decreto } 2.208 \text { regulamenta a educação profissional e cria o programa de Expansão da } \\
\text { Educação Profissonal (Proep). }\end{array}$ \\
\hline 2004 & IIIIte a IIItegr açau uo \\
\hline 2005 & $\begin{array}{l}\text { Institui-se, pela Lei } 11.195 \text {, que a expansão da oferta da educação profissional } \\
\text { preferencialmente ocorrerá em parceria com Estados, Municípios e Distrito Federal, setor } \\
\text { produtivo ou organizações não governamentais; Lançada a primeira fase do Plano de } \\
\text { Expansão da Rede Federal, com a construção de } 60 \text { novas unidades de ensino pelo } \\
\text { Governo Federal. O Cefet Paraná passa a ser Universidade Tecnológica Federal do } \\
\text { Paraná. }\end{array}$ \\
\hline 2006 & $\begin{array}{l}\text { O Decreto } 5.773 \text { trata sobre o exercício das funções de regulação, supervisão e avaliação } \\
\text { de instituições de educação superior e cursos superiores de graduação e sequenciais no } \\
\text { sistema federal de ensino. É instituído, no âmbito federal, o Programa Nacional de } \\
\text { integração da educação profissional com a educação de jovens e adultos. É lançado o } \\
\text { Catálogo Nacional dos Cursos Superiores de Tecnologia. }\end{array}$ \\
\hline 2007 & $\begin{array}{l}\text { Lançada a segunda fase do Plano de Expansão da Rede Federal. O Decreto } 6.302 \text { institui o } \\
\text { Programa Brasil Profissionalizado. É lançado o Catálogo Nacional dos Cursos Técnicos. }\end{array}$ \\
\hline
\end{tabular}

Fonte: MEC (2016).

Conforme demonstrado no quadro 2, a educação profissional foi se transformando ao longo do tempo e, após intenso processo de discussão e articulação, por meio da Lei 11.892/2008, é instituída a Rede Federal de Educação Profissional, Científica e Tecnológica. Em 2018, a rede era formada por 659 unidades em todo o país, das quais 643 já se encontravam em funcionamento, sendo dividida da seguinte forma: 02 Centros Federais de Educação, Ciência e Tecnologia; 23 Escolas Técnicas vinculadas às Universidades Federais; a Universidade Tecnológica Federal do Paraná; o Colégio Pedro II e os 38 Institutos Federais de Educação, Ciência e Tecnologia. Com uma estrutura multicampi, a rede configura-se hoje como importante estrutura para que as pessoas tenham efetivo acesso às conquistas científicas e tecnológicas (MEC, 2018).

A Estrutura dos Institutos Federais é descrita por Fernandes e Tabosa da seguinte forma: 
O Instituto Federal de Educação, Ciência e Tecnologia (IF), criado nos termos da Lei n ${ }^{o}$ 11.892, de 29 de dezembro de 2008, como instituição de educação superior, básica e profissional, pluricurricular e multicampi, especializada na oferta de educação profissional e tecnológica nas diferentes modalidades de ensino, no contexto da organização pública brasileira, se insere como entidade da administração indireta, com natureza jurídica de autarquia, detentora de autonomia didático-pedagógica, disciplinar, administrativa, patrimonial e financeira (FERNANDES E TABOSA, 2018. p. 24).

Sob a ótica administrativa, Frigotto (2018) traz algumas discordâncias sobre a gestão da rede pelo Ministério da Educação no que se refere a definição do Programa Nacional de Acesso ao Ensino Técnico e Emprego (PRONATEC) como política prioritária de formação profissional pelo governo, pela crescente ingerência no MEC do setor privado e pelo direcionamento dos recursos ao setor privado, em particular ao Sistema S. Isto se agrava pelo fato de os IFs não constituírem uma rede com o mesmo poder político. Em relação ao governo, constata-se também o esvaziamento de poder da SETEC/MEC (FRIGOTTO, 2018). Nessa mesma linha, para Moura (2013), o Programa Nacional de Acesso ao Ensino Técnico e Emprego (PRONATEC) é um exemplo emblemático na atualidade, pois se trata de cursos fora da perspectiva da formação humana integral prevista no Ensino Médio Integrado.

No entanto, Frigotto (2018) faz um balanço positivo em relação a rede em especial aos IFs:

Cabe ressaltar, todavia, que o balanço de pontos positivos da expansão, com a inclusão de milhares de jovens nessas instituições, pela geração de centenas de empregos qualificados e pela mudança que a interiorização impacta em todos os níveis, econômico, cultural e político, nas pequenas e médias cidades, é muito maior que os problemas. Ressaltamos a inclusão de quilombolas, índios e alunos provenientes de extratos populares que jamais teriam ingressado num ensino médio de qualidade e possibilidade de ensino superior sem a criação, expansão e interiorização dos IFs (FRIGOTTO, 2018. p. 148).

Segundo Pacheco (2011), os IFs são considerados como uma revolução histórica na educação profissional, eles são a síntese daquilo que de melhor a Rede Federal de Educação construiu ao longo de sua história e das políticas de educação profissional e tecnológica do governo federal. O projeto colocado em curso baseia-se na integração entre ciência, tecnologia e cultura como dimensões indissociáveis da vida humana e, ao mesmo tempo, no desenvolvimento da capacidade de investigação científica, essencial à construção da autonomia intelectual. Para Moura, Lima Filho e Silva (2015), os IFs significam a ampliação das possibilidades de muitos brasileiros, residentes nas periferias das capitais e nas regiões afastadas dos grandes centros urbanos, terem acesso a uma educação de qualidade. 
A concepção e diretrizes dos IFs envolvem sobrepor dicotomias entre ciência/tecnologia, entre teoria/prática; a superação da visão compartimentada de saberes; e a apropriação com maior profundidade do conhecimento, hoje em ritmo cada vez mais acelerado de construção e desconstrução (MEC, 2010). Nesse sentido, Ramos (2008) entende que não se deve defender uma formação profissional em detrimento da formação geral, mas uma formação profissional que possibilite aos sujeitos jovens e adultos se apropriarem de conhecimentos que estruturem sua inserção na vida produtiva dignamente.

Pacheco (2011) acredita que o objetivo central dos IFs é formar o cidadão que tanto poderia ser um técnico quanto um filósofo e por meio da escola cultivar a música, o teatro a literatura assim como as artes plásticas na busca da superação do preconceito de classe. Corroborando esse assunto, Moura, Lima Filho e Silva (2015) explicam que a dimensão intelectual abrange além das ciências da natureza e da matemática, as ciências humanas e sociais, a filosofia, as letras, as artes, enfim, a cultura.

\footnotetext{
Destarte, podemos afirmar que a formação para o trabalho dos Institutos Federais de Educação, Ciência e Tecnologia, ao se alicerçarem sob os ideais da formação omnilateral, permitem aos seus alunos, serem, não apenas técnicos, mas sim dirigentes das atividades que executam dentro do mundo da produção. Estes sujeitos, por compreenderem a dimensão ontológica do trabalho, têm a possibilidade e, principalmente, a potencialidade de romper com a face "estranha" do trabalho, compreendendo-o como uma atividade realizadora. Assim, o trabalho deixa de ser a alienante "certidão pra nascer e a concessão pra sorrir", cantada por Chico Buarque, tornando-se, ontologicamente, o veículo que faz o homem (re)nascer e sorrir (MOTA ARAÚJO e SANTOS, 2018, p. 362).
}

Voltando às características gerais dos Institutos Federais, a rede possuía em 2018 um total de 38 Institutos Federais com uma estrutura multicampi, dentre estes está o Instituto Federal de Educação, Ciência e Tecnologia do Norte de Minas Gerais, o qual será abordado seguir.

\section{OS DEZ ANOS DO INSTITUTO FEDERAL DE EDUCAÇÃO, CIÊNCIA E TECNOLOGIA DO NORTE DE MINAS GERAIS.}

Se nas demais regiões do Brasil a presença dos IFs foi importante, estar no Norte e Noroeste de Minas Gerais e Vales do Jequitinhonha e Mucuri nos últimos dez anos, regiões de desigualdade estrutural profunda, representa uma mudança visceral na vida das pessoas principalmente por potencializar uma educação que possibilita ao indivíduo o desenvolvimento de sua capacidade de gerar conhecimentos a partir de uma prática interativa com a realidade. 
Criado pela Lei 11.892, de 29 de dezembro de 2008, por meio da fusão da Escola Agrotécnica Federal de Salinas e Centro Federal de Educação Tecnológica de Januária, o IFNMG conta hoje com onze Campi e uma Reitoria. Em uma década de atuação, a instituição se coloca como referência na oferta de educação profissional, científica e tecnológica, apesar da crescente escassez de recursos (IFNMG, 2018).

Com uma organização estruturada no formato multicampi, as unidades estão localizadas nos seguintes municípios: Almenara, Araçuaí, Arinos, Diamantina, Januária, Montes Claros, Pirapora, Salinas e Teófilo Otoni. Possui também campus avançado nas cidades de Janaúba e Porteirinha. Dentre os campi citados, o de Januária e o de Salinas vêm contribuindo para o desenvolvimento científico e cultural da região por mais de 50 anos (IFNMG, 2018).

\section{Desafios}

A partir da análise do relatório de gestão do IFNMG de 2018 é possível destacar os principais desafios dessa instituição nos últimos 10 anos, conforme apresentados no quadro a seguir.

Quadro 4: Principais desafios enfrentados pelo IFNMG

\section{Desafios}

Política de expansão da Rede Federal de Educação Profissional, Científica e Tecnológica

Contingenciamento de recursos públicos

Atraso nas descentralizações de créditos orçamentários

Evasão dos estudantes

Não liberação de códigos de vaga para contratação de servidores

Criação de cursos de licenciatura e desenvolvimento de programas de formação inicial e continuada de professores.

Fonte: IFNMG (2018).

A política de expansão da Rede Federal de Educação, Científica e Tecnológica (RFECPT) foi apontada como uma ameaça observada no ambiente de atuação da instituição (IFNMG, 2018). Conforme é apontado por Frigotto (2018), um dos aspectos mais problemáticos a ser enfrentado pelos IFs diz respeito a expansão. Na interiorização das unidades foram criados campi ou campi avançados não acompanhados de pessoal suficiente, laboratórios, instalação em geral. Para o autor, a expansão interiorizada por pressões políticas locais forçou a criação de campi e campi avançados 
sem uma base material sólida e como consequência a diminuição das dotações orçamentárias devido à crise.

O subfinanciamento é uma das maneiras mais eficazes de conter qualquer possibilidade de oferta de educação de qualidade. Nesse sentido, a instituição também apontou o contingenciamento de recursos públicos e atrasos na descentralização de créditos orçamentários como uma ameaça aos seus propósitos. Com efeito da restrição financeira, várias metas pactuadas não foram atingidas conforme apontado pelo relatório de gestão (IFNMG, 2018). Logo, Frigotto (2018) aponta que nos últimos anos vem sendo imposto limites aos IFs, sobretudo, a PEC 241, que congela por vinte anos os investimentos na esfera pública, único âmbito em que se pode atender a direitos universais como a educação. Para o autor, nenhum processo educativo formal se faz com qualidade sem uma robusta base material que se expressa:

a) pela formação e pelo número adequado de docentes, pessoal técnico e de apoio e com tempo adequado em sala de aula, estudo, pesquisa e orientação dos alunos; b) pela estabilidade e continuidade na instituição deste corpo docente e técnico; c) pela existência de laboratórios para todas as áreas e materiais disponíveis e biblioteca adequada e atualizada não apenas no que é específico, mas naquilo que é fundamental a todas as ciências e artes; e d) espaços para esportes, lazer e atividades culturais, sem o que os jovens sentem-se aprisionados (FRIGOTTO, 2018. p. 144).

A evasão de estudantes também desponta como um fator desafiador para a Instituição que apesar das políticas desenvolvidas, no que se refere à permanência e ao êxito dos educandos, para o IFNMG, a evasão e repetência acontecem acima dos níveis aceitáveis, conforme diagnósticos realizados pelos campi para elaboração do Plano de Permanência e Êxito da instituição (IFNMG, 2018). Costa (2018) analisa que esse fenômeno pode estar associado a diversos motivos, tais como: a heterogeneidade do público atendido marcada pela discrepância de conhecimentos; histórico de evasão; o caráter altamente especializado dos cursos ofertados; o alto índice de retenção e a certificação antecipada através do ENEM.

O IFNMG (2018) aponta que a não liberação de códigos de vaga para contratação de servidores tem se tornado uma ameaça para as atividades da escola. Como já foi citado, não é possível um processo educativo adequado sem um número apropriado de docentes, pessoal técnico e de apoio. Além disso, Costa (2018) acrescenta o grande número de remoções e redistribuição de servidores agravando um cenário já deficitário marcantemente nos campi situados no interior.

Finalizando os desafios de maior amplitude, de acordo com relatório de gestão, seja por falta de professores para o atendimento da demanda ou por falta de infraestrutura, a meta de criação de 
cursos de licenciatura e desenvolvimento de programas de formação inicial e continuada de professores, não foi atingida por alguns campi IFNMG (2018). A formação desses profissionais nos IFs tem sido importante para aproximar as secretarias de educação e beneficiar os sistemas locais de educação, uma vez que boa parte das licenciaturas dialoga com um eixo tecnológico de conhecimento que está previsto como foco dos campi (PACHECO, 2015).

\section{Conquistas}

O IFNMG tem muitas conquistas a ser celebradas no final de uma década, o número de alunos matriculados, chegou em 2018 com um total de 17.521 (dezessete mil e quinhentos e vinte um), conforme apresentado na Tabela 1 .

Tabela 1. Número de alunos Matriculados

\begin{tabular}{|c|c|c|c|}
\hline Nível & Modalidade EaD & Modalidade Presencial & Total \\
\hline Técnico $^{3}$ & 2423 & 4928 & 7351 \\
\hline Superior & 1678 & 4466 & 6144 \\
\hline Pós - graduação & 2294 & 74 & 2368 \\
\hline $\begin{array}{c}\text { Formação Inicial e } \\
\text { Continuada (FIC) }\end{array}$ & 1148 & 510 & 1658 \\
\hline Total & 7543 & 9978 & 17521 \\
\hline
\end{tabular}

Fonte: IFNMG em Números (2018).

Para Moura, Lima Filho e Silva (2015) os IFs significam a presença do Estado brasileiro ofertando educação de qualidade nas periferias das capitais e em regiões afastadas dos grandes centros urbanos, ampliando as possibilidades de muitos brasileiros terem acesso a uma educação de qualidade, posto que, atualmente, são poucas as redes estaduais com condições para garantir esse direito à população. Segundo Aguiar e Pacheco (2017), além de um relevante compromisso civilizatório que nega a alienação, a educação científica e tecnológica é uma condição para o exercício do direito ao acesso de cada cidadão aos benefícios gerados pela humanidade.

\footnotetext{
${ }^{3}$ Dos 4.928 alunos matriculados nos cursos técnicos presenciais, 2.984 são dos cursos integrados ao ensino médio.
} 
Outra conquista que deve ser enfatizada são os 29 (vinte e nove) cursos técnicos integrados ao ensino médio com um total de 2.984 (dois mil e novecentos e oitenta e quatro) alunos matriculados (IFNMG, 2018). Ofertar ensino médio integrado a educação profissional, sob uma base unitária de formação geral é uma condição necessária para se fazer a travessia para a educação politécnica e omnilateral realizada pela escola unitária (CIAVATTA, 2014). Sobre esse assunto, Araújo e Frigotto (2015) explicam que o ensino integrado é uma proposição pedagógica que se compromete com a utopia de uma formação inteira, que não se satisfaz com a socialização de fragmentos da cultura sistematizada e que compreende como direito de todos ao acesso a um processo formativo, inclusive escolar, que promova o desenvolvimento de suas amplas faculdades físicas e intelectuais.

$\mathrm{Na}$ defesa do ensino médio integrado, Ramos (2007) entende que tanto é possível como necessário, em uma realidade conjunturalmente desfavorável, em que os filhos dos trabalhadores precisam obter uma profissão ainda no nível médio, não podendo adiar este projeto para o nível superior de ensino, mas ele pode potencializar mudanças para, superando-se essa conjuntura, constituir-se em uma educação que contenha elementos de uma sociedade justa. Nessa mesma linha de pensamento, Ciavatta (2014) também entende que ele é um ensino possível e necessário aos filhos dos trabalhadores. Porém, tendo como fundamento a integração entre trabalho, ciência e cultura, esse tipo de ensino acirra contradições e potencializa mudanças.

Assim, o termo integrado remete-se, por um lado, à forma de oferta do ensino médio articulado com a educação profissional; mas, por outro, também a um tipo de formação que seja integrada, plena, vindo a possibilitar ao educando a compreensão das partes no seu todo ou da unidade no diverso (CIAVATTA, 2014. p. 198).

Ainda sobre o ensino médio integrado, Ramos (2014) explica que, este é um meio pelo qual as pessoas se realizam como sujeitos históricos que produzem sua existência pelo enfrentamento consciente da realidade dada, produzindo valores de uso, conhecimentos e cultura por sua ação criativa.

Outro motivo de celebração do IFNMG vem da Política de Assistência Estudantil, protagonizada pela Diretoria de Assuntos Estudantis e Comunitários e seus respectivos núcleos, com 12.794 (doze mil e setecentos e noventa e quatro) auxílios concedidos referentes ao Programa de Assistência e Apoio Financeiro aos Discentes em Situação de Vulnerabilidade Social - Tabela 2. 
Tabela 2. Auxílios financeiros concedidos

\begin{tabular}{|c|c|}
\hline Tipo de Auxílio & Quantidade \\
\hline Permanência & 1.213 \\
\hline Alimentação & 3.053 \\
\hline Transporte & 3.681 \\
\hline Moradia & 1.182 \\
\hline Cópia impressão & 1.009 \\
\hline $\begin{array}{c}\text { Emergencial } \\
\text { Auxílio financeiro } \\
\text { viagem }\end{array}$ & 18 \\
\hline Total de auxílios & 12.638 \\
\hline
\end{tabular}

Fonte: IFNMG em números (2018).

Aos auxílios financeiros relacionados na tabela 2, somam se às 224 (duzentos e vinte quatro) bolsas concedidas referentes ao Programa Bolsa Permanência do Ministério da Educação (MEC) para alunos indígenas, quilombolas e em vulnerabilidade social - Tabela 3.

Tabela 3. Bolsas Concedidas MEC

\begin{tabular}{|c|c|}
\hline Discente & Quantidade \\
\hline Indígena & 7 \\
\hline Quilombola & 78 \\
\hline Vulnerável & 139 \\
\hline Total de bolsas concedidas & 224 \\
\hline
\end{tabular}

Fonte: IFNMG em números (2018).

O IFNMG tem como proposta promover continuamente a educação inclusiva, buscando a implementação, integração e fortalecimento de ações, mecanismos e estratégias que garantam a democratização do acesso, permanência, o êxito escolar/acadêmico e a redução das taxas de evasão e retenção (IFNMG 2018).

A importância desses auxílios financeiros é retratada pelos autores Moura, Lima Filho e Silva (2015). No Brasil, a extrema desigualdade socioeconômica obriga grande parte dos filhos da classe trabalhadora a buscar, bem antes dos 18 anos de idade, a inserção no mundo do trabalho, visando complementar a renda familiar ou até a autossustentação. Soares (2015) entende que sendo garantidos esses mínimos sociais, existe uma possibilidade de se garantir o sucesso escolar. Na 
visão da autora a democratização trazida juntamente com esses programas de expansão da educação não deve oportunizar somente o acesso, mas proporcionar mecanismos de permanência e conclusão nos cursos.

Segundo Gramsci (1982), a escola unitária requer que o Estado possa assumir as despesas que hoje estão a cargo da família, no que toca à manutenção dos escolares, isto é, que seja completamente transformado o orçamento da educação nacional, ampliando-o de um modo imprevisto e tornando-o mais complexo. Nesse sentido, os sistemas e as instituições não podem estar alheios às necessidades materiais para levar adiante um processo educacional dessa natureza. Por exemplo, as necessidades dos alunos para cumprir a jornada de estudos, em termos de locomoção, de alimentação, de renda mínima para se manter e manter-se na escola (RAMOS, 2014).

\section{CONCLUSÃO}

Conforme o que foi apresentado, o Brasil possui um histórico de desigualdade educacional estrutural e tem um longo caminho a percorrer na oferta de educação profissional de qualidade para todos, em especial, na criação e ampliação de escolas técnicas teóricas e práticas que tenha o trabalho como princípio educativo. Nesse processo, o IFNMG, no final de uma década de existência, tem encontrado diversos desafios como: uma expansão sem uma base material sólida; contingenciamento e atrasos de recursos; evasão de alunos; código de vagas insuficientes para a contratação de servidores, dentre outros.

Contudo, para uma instituição com dez anos, o IFNMG já coleciona conquistas, tais como: o número expressivo de alunos matriculados caracterizando a inclusão dos filhos de trabalhadores nesse processo; os diversos cursos de educação profissional integrados ao ensino médio possibilitando uma formação integrada, plena, vindo a permitir ao educando a compreensão das partes no seu todo ou da unidade no diverso; uma política de assistência ao aluno com uma expressividade de alunos em vulnerabilidade social atendidos possibilitando a permanência e êxito na vida escolar.

Pela observação dos aspectos analisados, pode se concluir que os resultados encontrados ainda indicam uma sobreposição das conquistas sobre os desafios do IFNMG nesse processo apontando que a grande disputa, portanto, não só do coletivo de dirigentes, professores, técnicos e servidores, mas do sindicato, pais e alunos, das comunidades locais e do poder público, não é retroceder, mas de ampliar e qualificar a grande conquista que é o próprio IFNMG para prosseguir 
na travessia, pois conforme aponta Ciavatta $(2014$, p. 197) “é incipiente a participação da população na reivindicação de um sistema educacional público, gratuito e de qualidade para todos”.

\section{REFERÊNCIAS}

AGUIAR, Luiz Edmundo Vargas de; PACHECO, Elieser Moreira. Os institutos federais de educação, ciência e tecnologia como política pública. In: ANJOS, Mayla Brandão dos; RÔÇAS, Gisele. (Orgs.). As políticas públicas e o papel social dos institutos federais de educação, ciência e tecnologia. Natal: editoraifrn, 2017. p. 13-35.

BRASIL, Ministério da Educação. Linha do Tempo: Rede Federal de Educação, Profissional, Científica e Tecnológica. 2016. Disponível em: <

http://redefederal.mec.gov.br/images/pdf/linha_tempo _11042016.pdf >. Acesso em: jan. 1019.

BRASIL, Ministério da Educação. Secretaria de Educação Profissional e Tecnologia. Instituto

Federal de Educação, Ciência e Tecnologia: um novo modelo em educação profissional e tecnológica. 2010. Disponível em: <

http://portal.mec.gov.br/index.php?option=com_docman\&view=download\&alias=6691-ifconcepcaoediretrizes\&category_slug=setembro-2010-pdf\&Itemid=30192> . Acesso em: 10 Jan.2019.

COSTA, Pedro Luiz de Araujo. A educação do campo no contexto da implementação dos IFs no Estado do Rio de Janeiro. In: FRIGOTTO, Gaudêncio. (org.) Institutos Federais de Educação, Ciência e Tecnologia: relação com o ensino médio integrado e o projeto societário de desenvolvimento. Rio de Janeiro: UERJ, LPP, 2018. p. 151-204.

CUNHA, Luiz Antônio. O ensino industrial-manufatureiro no Brasil. Rev. Bras. Educ., Rio de Janeiro , n. 14, p. 89-107, ago. 2000 . Disponível em: <http://www.scielo.br/scielo.php?script= sci_arttext\&pid=S1413-24782000000200006\&lng=pt\&nrm=iso>. Acesso em: 07 jan. 2019.

ESCOTT, Clarice Monteiro; MORAES, Márcia Amaral Correa de. História da educação profissional no Brasil: as políticas públicas e o novo cenário de formação de professores nos institutos federais de educação, ciência e tecnologia. João Pessoa. 2012. Disponível em: <http://www.histedbr.fe.unicamp.br/acer histedbr/seminario/seminario9/PDFs/2.51.pdf > . Acesso em: 11 jan. 2019.

FERNANDES, Francisco Das Chagas De Mariz; TABOSA, Wyllys Abel Farkatt. Instituto Federal: uma organização composta de organizações. Editora Ifrn. Rio Grande de Norte. 2018.

FONSECA, Celso Suckow. História do Ensino Industrial no Brasil. Rio de janeiro: Escola Técnica, 1961. Disponível em: <https://pt.scribd.com/document/327224020/FONSECA-CelsoSuckow-Historia-do-Ensino-Industrial-no-Brasil-pdf >. Acesso em: 07 jan. 2019.

FRIGOTTO. Gaudêncio. Indeterminação de identidade e reflexos nas políticas institucionais formativas dos IFs. In: FRIGOTTO, Gaudêncio. (org.). Institutos Federais de Educação, Ciência e Tecnologia: relação com o ensino médio integrado e o projeto societário de desenvolvimento. Rio de Janeiro: UERJ, LPP, 2018. p. 125-150. 
GARCIA, Sandra Regina de Oliveira. O Fio da história: a gênese da formação profissional no Brasil. Anped. 2000. Disponível em: <http://www.anped.org.br/biblioteca/item/o-fio-da-historiagenese-da-formacao-profissional-no-brasil>. Acesso em: 07 jan. 2019.

GIL, Antônio Carlos. Métodos e técnicas de pesquisa social. 2. ed. São Paulo: Atlas. 1989.

GIL, Antônio Carlos. Métodos e técnicas de pesquisa social. 6. ed. São Paulo: Atlas. 2008.

GRAMSCI, Antônio. Os intelectuais e a organização da cultura. Rio de Janeiro: Editora Civilização Brasileira S.A. 1982.

INSTITUTO FEDERAL DO NORTE DE MINAS GERAIS. IFNMG em números. Disponível em: < https://drive.google.com/file/d/1tpMtvNTF0ErUWD-YdJxTvTHsy3wCGbTk/view>. Acesso em: 17 jan. 2019.

INSTITUTO FEDERAL DO NORTE DE MINAS GERAIS. Plano de desenvolvimento institucional- PDI: vigência de 2019 a 2023. Reitoria do IFNMG. 2018. Disponível em: < https://www.ifnmg.edu.br/docs-planejamento>. Acesso em: 16 jan. 2019.

INSTITUTO FEDERAL DO NORTE DE MINAS GERAIS. Relatório de gestão do exercício de 2017. Reitoria do IFNMG. Montes Claros. 2018. Disponível em: < https://www.ifnmg.edu.br/relatorio-gestao>. Acesso em: 16 jan. 2019.

KUENZER, Acácia Zeneida. Educação e trabalho no Brasil: o estado da questão. Brasília : INEP. 1991.

LUDKE, Menga; ANDRÉ, Marli Eliza Dalmazo Afonso de. Pesquisa em educação: abordagens qualitativas. São Paulo: EPU, 1986.

MOTA, Karla Rodrigues; ARAÚJO, Cláudia Helena dos Santos; SANTOS, Bruno Gonçalves dos. A formação para o trabalho: o papel dos institutos federais na produção dos novos intelectuais.

HOLOS, [S.1.], v. 2, p. 351-364, jun. 2018. ISSN 1807-1600. Disponível em:

<http://www2.ifrn.edu.br/ojs/index.php/HOLOS/article/view/7120>. Acesso em: 10 jan. 2019.

MOURA, Dante Henrique. Educação básica e educação profissional e tecnológica: dualidade histórica e perspectivas de integração. HOLOS, Ano 23, Vol. 2 - 2007. ISSN 1807-1600.

Disponível em: 〈http://www2.ifrn.edu.br/ojs/index.php/HOLOS/article/view/11>. Acesso em: 07 jan. 2019.

MOURA, Dante Henrique; LIMA FILHO, Domingos Leite; SILVA, Mônica Ribeiro. Politecnia e formação integrada: confrontos conceituais, projetos políticos e contradições históricas da educação brasileira. Rev. Bras. Educ., Rio de Janeiro, v. 20, n. 63, p. 1057-1080, dez. 2015 . Disponível em: <http://www.scielo.br/scielo.php?script=sci_arttext\&pid=S1413-24782015000401057\&lng=pt \&nrm=iso $>$. Acesso em 10 jan. 2019.

MOURA, Dante Henrique. Ensino médio integrado: subsunção aos interesses do capital ou travessia para a formação humana integral?. Educ. Pesqui., São Paulo, v. 39, n. 3, p. 705-720. 
Set. 2013. Disponível em: <http://www.scielo.br/scielo.php?script=sci_arttext\&pid=S151797022013000300010\&lng=en\&nrm=iso>. acesso em: 11 jun. 2019.

NARCISO, Luciana Gusmão de Souza. Análise da Evasão nos Cursos Técnicos do Instituto Federal do Norte de Minas Gerais - Campus Arinos: exclusão da escola ou exclusão na escola?, Dissertação (Mestrado)- Universidade Federal de Santa Catarina. Santa Catarina, 2015.

PACHECO, Elieser. Fundamentos políticos-pedagógicos dos institutos federais: diretrizes para uma educação profissional e tecnológica transformadora. IFRN Editora. Natal. 2015.

PACHECO, Elieser. Institutos Federais: uma revolução na educação profissional e tecnológica. Moderna. São Paulo. 2011.

PIRES, Angélica Monteiro Soares. Assistência estudantil como garantia do direito à educação: ações de uma equipe interdisciplinar que promovem o acesso, permanência e formação dos estudantes de ensino técnico e superior. Brasília: UNB. 2015. Disponível em:

<http://bdm.unb.br/bitstream/10483/14691/1/2015_AngelicaMonteiroSoaresPires_tcc.pdf $>$. Acesso em: jan. 2019.

RAMOS, Marise Nogueira. Concepção do ensino médio integrado. Secretaria de Educação do Estado do Rio Grande do Norte. Rio Grande do Norte. 2007. Disponível em:

http://forumeja.org.br/go/sites/forumeja.org.br.go/files/concepcao_do_ensino_medio_integrado5.pd f> . Acesso em: 10 jan. 2019.

RAMOS, Marise Nogueira. História e política da educação profissional. Curitiba: IFPR-EAD. 2014.

SEVERINO, Antônio Joaquim. Metodologia do trabalho científico. São Paulo: Cortez, 2007. 